\title{
Push-out Tests for Determining Shear Strength and Stiffness of Perfobond Connector-Experimental Study
}

\author{
Khawla A. Farhan ${ }^{a}$ and Muhaned A. Shallal ${ }^{a *}$ \\ ${ }^{a}$ Civil Engineering Department, College of Engineering, University of Al-Qadisiyah
}

\begin{tabular}{l} 
A R T I C L E I N F O \\
\hline Article history: \\
Received 03 October 2019 \\
Received in revised form 14 Novem \\
Accepted 21 November 2019 \\
Keywords: \\
Concrete-filled steel tube (CFST) \\
Lightweight concrete \\
Push-out test \\
Perfobond connector \\
Reinforced concrete \\
Compressive strength
\end{tabular}

\begin{abstract}
A B S T R A C T
This study presents an experimental investigation for push-out tests in order to evaluate the performance of continuous perfobond connectors. A total of five specimens composed of light-weight concrete-filled steel tubes (square and circle sections) with two reinforced blocks were tested. The measured parameters are the compressive strength of the concrete blocks and the type of the section. The specimens were tested under a concentric load applied on the steel tube filled with lightweight concrete; the corresponding slip value was measured using two LVDTs. The experimental results showed that the ultimate shear strength and stiffness of the square steel tube filled with concrete were higher than that of circular samples. The ultimate shear strength and stiffness increased with an increase of concrete compressive strength, while the corresponding slips showed decreasing in their values with increase of the compressive strength of the concrete.
\end{abstract}

\section{Introduction}

The most important feature for design the composite structure is a loadslip relationship because it is going to set the linear and nonlinear behavior of the shear connection. The push-out tests are a very appropriate way to determine this relationship. The earlier studies were focused on the stud connectors, with different diameters, lengths, and spaces between the connectors. There are some proposed expressions to predict the load-slip relationship for the stud connector [1-3]. Many types of connectors are available such as perfobond ribs, Oscillatingperfobond strip shear connector, corrugated shear connector waveformstrip shear connector, and perfobond connector, as shown in Fig. 1. The perfobond connector can be used in several applications such as connecting the CFST (concrete filed steel tube) members with concrete beam, foundation or slab, as shown in Fig. 2. Three-stages in the curve of the load- slip of perfobond connector for push out test usually obtained, as shown in Fig. 3 [4]. The initial stage is elastic in which the loading followed the linear elastic relationship untill the initial slip $\left(\mathrm{s}_{\mathrm{i}}\right)$ of perfobond connector and the equivalent load was the yield strength $(\mathrm{Vy})$. The shear stiffness Ks of perfobond connector is equal to $\left(\mathrm{Vy} / \mathrm{s}_{\mathrm{i}}\right)$. The second stage is the Elasto-plasto stage in which the shear load increases until the ultimate load (peak point) is reached.

* Corresponding author.

E-mail address: Mohanad.Shallal@qu.edu.iq ( Muhaned A. Shallal) 


\author{
Nomenclature \\ Cp $\quad$ specific heat $\left(\mathrm{J} \mathrm{kg}^{-1} \mathrm{~K}^{-1}\right)$ \\ $g \quad$ gravitational acceleration $\left(\mathrm{m} \mathrm{s}^{-2}\right)$ \\ $k \quad$ thermal conductivity $\left(\mathrm{W} \mathrm{m}^{-1} \mathrm{~K}^{-1}\right)$ \\ $k r \quad$ thermal conductivity ratio, $\mathrm{kr}=\mathrm{kw} / \mathrm{kf}$ \\ $L \quad$ length of the enclosure (m) \\ $\mathrm{Lb} \quad$ baffle length (m) \\ Nul local Nusselt number along with the heat source \\ $\mathrm{Nu} \quad$ average Nusselt number \\ $p \quad$ pressure $\left(\mathrm{kg} \mathrm{m}^{-1} \mathrm{~s}^{-2}\right)$ \\ $P \quad$ non-dimensional pressure \\ $\mathrm{Pr} \quad$ Prandtl number \\ $\mathrm{Ra} \quad$ Rayleigh number \\ $T \quad$ dimensional temperature \\ $U \quad$ non-dimensional velocity component $\mathrm{X}$-direction \\ $Y \quad$ non-dimensional Y-coordinates
}

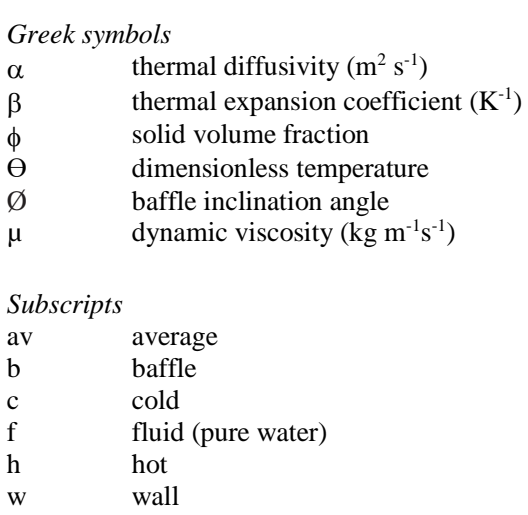

At this stage the maximum load is known as ultimate shear strength and the equivalent slip is known as the ultimate slip. The last stage is the Post failure stage, which appears after the ultimate shear strength is obtained. Beyond the ultimate shear strength, the slip shows continues, while the shear load $\mathrm{V}$ tends to decrease. Many studies have been conducted to investigate the performance of perfobond connector. Also, some expressions were suggested to expect the load slip relation for different types of perfobond connectors.

Zheng et al. [6] were testing seventy-two samples to get the performances of perfobond connectors using push-out tests. The tested parameters were the actions of using different strengths of very long sentences: concrete such as, varying the hole geometry, the arrangement of the reinforcement in holes, the size of the concrete slab, and the dimensions of the perfobond rib. An appropriate model was proposed to definite perfobond connector load-slip relationship casing a wide range of design parameters.

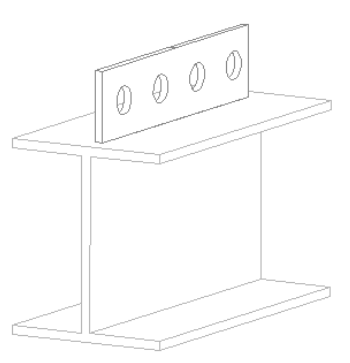

(a) perfobond ribs

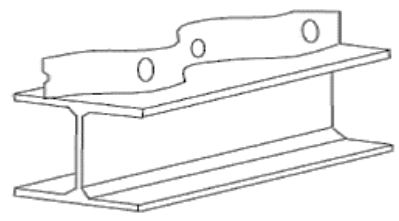

(c) Oscillating- perfobond strip

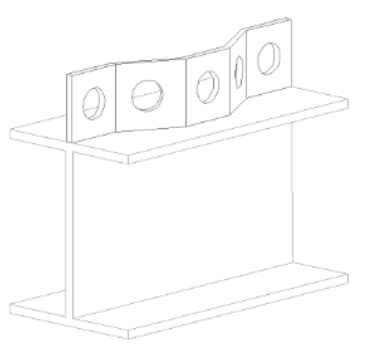

(b) corrugated perfobond strip

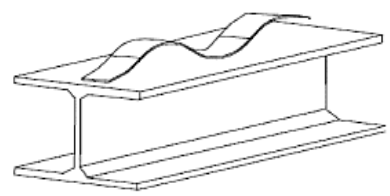

(d) waveform-strip

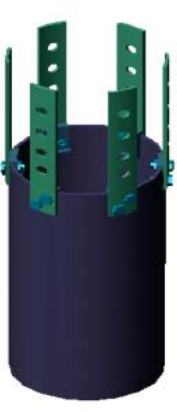

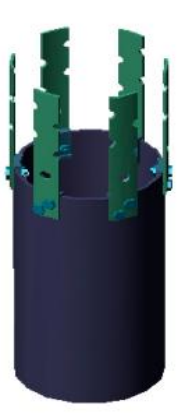

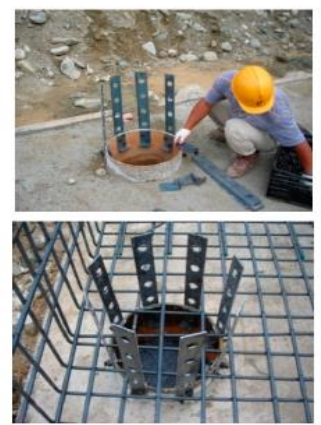

(a) Strengthening of the pile cap

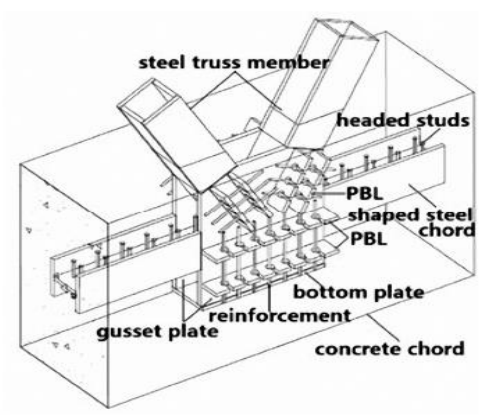

(b) composite trusses.

Figure 2. Perfobond connectors [6].

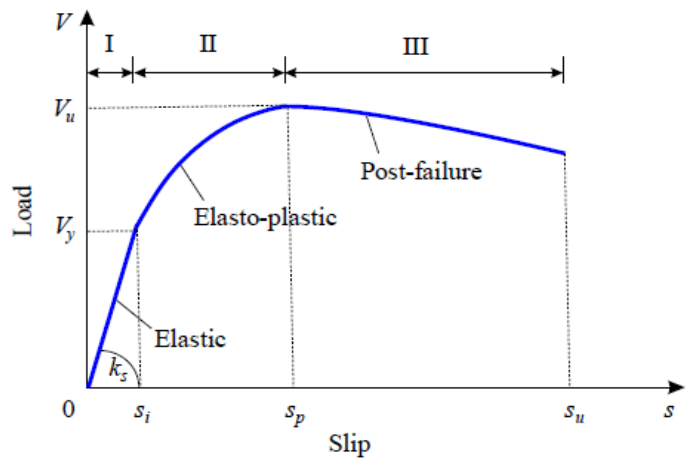

Figure 3. stage identifications [4]

Figure 1. Types of perfobond shear connectors [5].

Oguejiofort and Hosain [7] carried out a numerical study for the behavior of the perfobond connector using the finite element technique. The main 
purpose of this study was to find the ultimate capacity of the perfobond connector. It was noticed that the predicted capacities gotten by the equations resulting from the numerical study were in a good arrangement when compared with the investigational results of the push-out test. Ahn et al. [8] studied the behavior of the single and twin perfobond connectors. They described the perfobond connector between the high-strength concrete beam and steel section. Push out test has been conducted for this connector and study the effects of changing the strength of the concrete, the existence of transverse reinforcement in the holes of the connector, concrete end-bearing zone, and the arrangement of perfobond connector. Shear strength was measured through push out test. The main purpose of the study is to find the best arrangement of the perfobond connector and optimum design of the shear connector to use in the design of the concrete-steel girder system. The results obtained were compared with other studies and with shear capacity equations derived from the numerical studies. From the results, the equations that take into account the perfobond ribs arrangement derived and compared with prior equations. The comparison between the values found for single perfobond connector with transverse reinforcement were underestimated, But for twin perfobond connector the values were overestimated and so an improved shear capacity equation was proposed based on the analysis of the result. Zheng. et al. [9] presented a study on the ultimate shear capacity of perfobond shear connector. The researchers tested twenty-one samples. The major goal was to find a shear capacity, shape of failure, and slip performance of perfobond connectors. Eighty-seven numerical models were done to additional study the effects of concrete strength and hole shape. The parametric consequences created to calculate the equations of shear strength for perfobond connectors. Finally, an analytical model proposed to predict the shear capacity of both long and circular hole of perfobond connectors. This model depended on a hole size, transverse bar area, concrete strength and yield strength of the transverse bar. SU and Wang [10] developed a new type of connector used in a composite structure. They used a corrugated connector and tested it using a push-out test. They found that the performance of the corrugated connector was very good. The researchers compared with the properties of perfobond connector that gained from the push-out test. Shear capacity of corrugated connector was higher than that of perfobond connector by 24 percent. The stiffness of the corrugated connector was higher than of the perfobond connector. The load-slip curve of the corrugated connector was found using push-out tests. Relative stiffness expressions under the ultimate capacity and service state can also computed these tests. $\mathrm{Li}$ et al. [11] investigated the load-slip performance and failure characteristics for corrugated connector by pushout test and numerical technic. The results indicated that the shear strength of corrugated connector was affected by several factors such as the strength of concrete, perfobond reinforcement yield strength, the open area of steel plate, cross-sectional area, and horizontal projection area of corrugated connector. The concrete shear stiffness bars effect on the shear stiffness of corrugated connector in the elastic stage. A new mixed type of combined connectors was suggested by Zheng et al. [12]. The researchers used a stud connector with perfobond connector together. They designed nine specimens and tested them. A comparison between studs, perfobond connector, and the mixed connector in shear strength and the load-slip performance was performed. Furthermore, numerical models were produced to study additional the performances of combined shear connectors relating to material properties and connector dimension. They concluded that the shear capacity of the mixed shear connector increase with increasing rebar diameter, stud size, stud properties, hole diameter, concrete strength, and rebar properties. The curves of the load slip relationship that gained from finite element study were close to the tested results. Ibrahim et al. [13] conducted an experimental study on the shear. Four groups were formulated and tested under twelve push-out tests. These groups consisted of three types of shear connectors (stud, angle, and perfobond connectors). The researchers studied the behavior of shear connector, calculating the stiffness, and shear strength of these connectors. The results were concentrated on failure modes, strength, load-slip curves, and stiffness of the connectors. The results obtained showed very close behavior (shear resistance and stiffness) between Ishape and circular tube when using studs in two sections but the shear capacity of the perfobond connector higher than the shear capacity of the stud and angle connector. Zheng et al. [14] proposed an alternative notched perfobond connector to make it easy for installation of perforating reinforcement bars, because of difficulties of perforating the rebar inside the holes of classic perfobond connector with multi-ribs in bridges. This study showed the result of the push-out test for six samples which tested to failure. The major objective was to comparing between the behavior of perfobond connector with circular holes and the perfobond connector with notched holes in terms of shear capacity, slip behavior and failure mode. Also, forty-three nonlinear simulations were performed to study some variables and their effects like hole distance, hole number, hole diameter, rebar diameter, steel strength, and rebar strength. The final analytical model was proposed to calculate the shear strength of perfobond connector. The relationship between the slip and horizontal shear resistance in perfobond connectors depending on the number of perfobond connectors and the reinforcement bar properties that used in the holes of the perfobond connector. This study used a continues perfobond connector with a concrete-filled steel tube (CFST) to investigate the effect of bars in a connector only. The concrete used for filling the steel tube is lightweight. Three different mixes were used to understand the effect of concrete compressive strength used in concrete blocks on the slip; also, the two-section type used of CFST.

\section{Experimental program}

Five samples were prepared for testing push out behavior. Each sample consists of a concrete-filled steel tube of $500 \mathrm{~mm}$ length and two reinforced concrete blocks of $500 \times 450 \times 75 \mathrm{~mm}$. A lightweight concrete mixture was used to fill the steel tube. The details of the tested samples are listed in Table 1. The samples were named as two sections, S or C appointed to the section type of steel tube, $\mathrm{S}$ means square, and $\mathrm{C}$ means circular. The strength of concrete blocks was marked next to former notions as $(55,45$, and $35 \mathrm{MPa})$. The samples were connected with both sides to concrete block by perfobond connector, as shown in Fig. 4. Perfobond connector with dimensions $450 \times 50 \times 8 \mathrm{~mm}$ has holes with a diameter of $10 \mathrm{~mm}$, which used to pass the steel reinforcement bar for each section. The strength of infill concrete in tubes was the same lightweight concrete- for all samples. Two (LVDT) were used one on each block to record the slip between the steel tube and the concrete block. The arrangement of this test was according to Eurocode 4 [15].

\section{Material Properties}

Three types of normal concrete were used for concrete blocks and one lightweight concrete mix was used in CFST. The concrete-filled in tubes was a lightweight concrete formulated using gravel with a maximum size 
of $1.0 \mathrm{~cm}$ as check it (LECA). Details of concrete mixtures, density, and cubic compressive strength are listed in Table 2.

The values of yield stress and ultimate strength of the steel reinforcement, steel tubes, and perfobond connector are summarized in Table 3 .

Table 1. Details of specimens

\begin{tabular}{llll}
\hline \multirow{2}{*}{ Specimen } & \multirow{2}{*}{ Section type } & $\begin{array}{l}\text { Compressive strength (MPa) } \\
\text { Concrete block }\end{array}$ & CFST \\
\hline S-35 & Square & 35 & 20 \\
S-45 & Square & 45 & 20 \\
S-55 & Square & 55 & 20 \\
C-35 & Circular & 35 & 20 \\
C-55 & Circular & 55 & 20 \\
\hline
\end{tabular}

Table 2. Properties of mixing concrete

\begin{tabular}{llllll}
\hline & $\begin{array}{l}\text { Mixing } \\
\text { ratio }\end{array}$ & $\begin{array}{l}(\mathbf{W} / \mathbf{C}) \\
\text { ratio }\end{array}$ & S. P & $\begin{array}{l}\text { fcu } \\
\left(\mathbf{N} / \mathbf{m m}^{2}\right)\end{array}$ & $\begin{array}{l}\text { Density } \\
\left(\mathbf{k g} / \mathbf{m}^{3}\right)\end{array}$ \\
\hline LWC=20 & $1: 1.744: 0.5$ & 0.3 & $1 \%$ & 21.85 & 1790 \\
M2=55 & $1: 1.47: 2.2$ & 0.3 & $0.5 \%$ & 52.17 & 2518 \\
M3=45 & $1: 1.89: 2.84$ & 0.4 & $0.3 \%$ & 47.93 & 2340 \\
M4=35 & $1: 2.67: 4$ & 0.5 & - & 35.14 & 2250 \\
\hline
\end{tabular}

Table 3 steel properties.

\begin{tabular}{lll}
\hline Component & fy (MPa) & fu (MPa) \\
\hline Square tube & 390 & 433 \\
Circular tube & 305 & 391 \\
Steel reinforcement bar & 464 & 606 \\
Perfobond connector & 357 & 370 \\
\hline
\end{tabular}

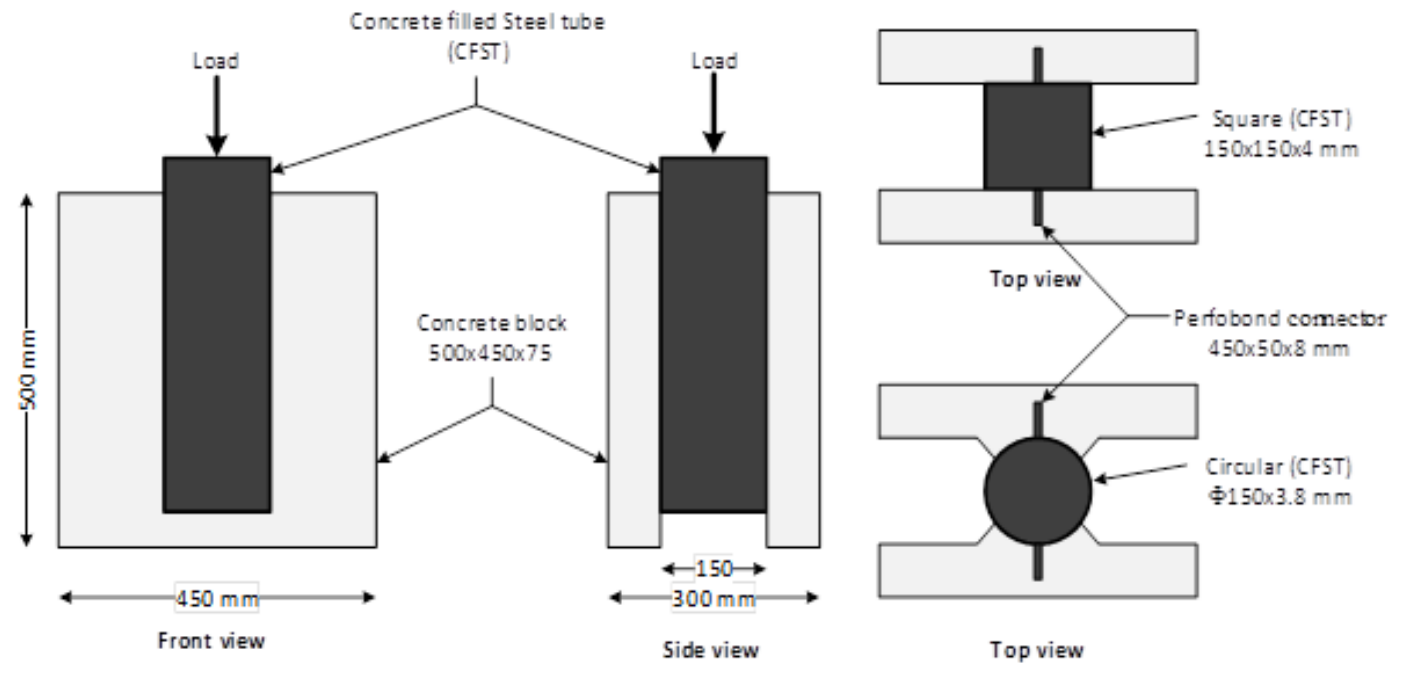

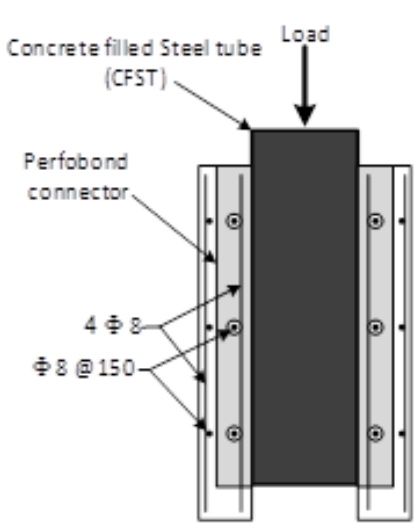

Side view

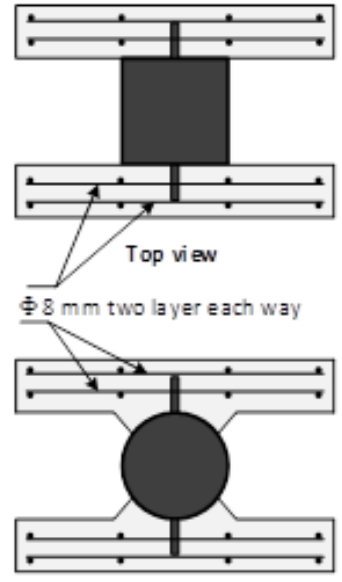

Top view

Figure 4. Specimen details. 


\section{Testing procedure}

The load applied with increases of $5 \mathrm{kN}$; the procedure of investigation was in agreement with Eurocode 4 [15]. For all tested samples two of LVDTs were used to record the displacement between concrete blocks and CFST; the locations of LVDTs, as shown in Fig. 5.

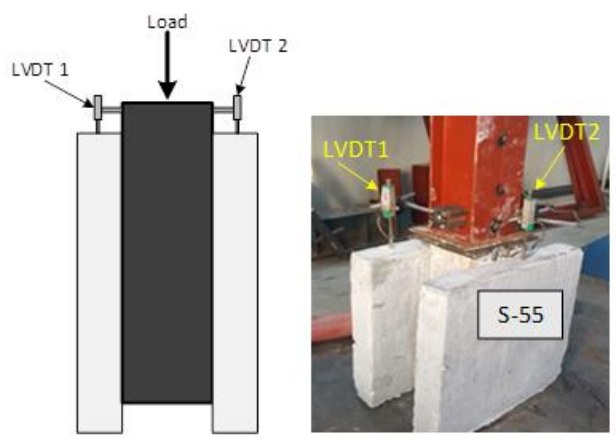

Figure 5 Slipping test

\section{Results and Discussions}

The results obtained from the tests are listed in Table 4. The load-slip relation of all samples is shown in Fig. 6. The tests were continued until the sample is completely failed. There were two signs of failure, the first is the appearance of a longitudinal crack parallel to the perfobond connector and the second is crushing in both concrete blocks, as shown in Fig. 7. For knowing what happens for reinforcement bars that used in the connectors, the concrete in both blocks was removed. After the extraction of reinforcement bars, it was found that some reinforcement had cut and the other had a very large deformation, as shown in Fig. 8.

Table 4. Result of the push-out test

\begin{tabular}{llllll}
\hline Specimen & $\mathrm{Vu}(\mathrm{kN})$ & $\mathrm{Vy}(\mathrm{kN})$ & $\mathrm{Si}(\mathrm{mm})$ & $\mathrm{S}_{\mathrm{P}}(\mathrm{mm})$ & $\mathrm{Ks}(\mathrm{kN} / \mathrm{mm})$ \\
\hline S-55 & 608.34 & 347.89 & 0.916 & 6.83 & 379.79 \\
$\mathrm{~S}-45$ & 575.2 & 325.98 & 0.993 & 8.16 & 328.28 \\
$\mathrm{~S}-35$ & 558.32 & 301.72 & 1.95 & 10.43 & 154.72 \\
$\mathrm{C}-55$ & 590.27 & 325.98 & 1.393 & 8.19 & 234.01 \\
$\mathrm{C}-35$ & 541.50 & 272.50 & 1.549 & 9.99 & 175.92 \\
\hline
\end{tabular}

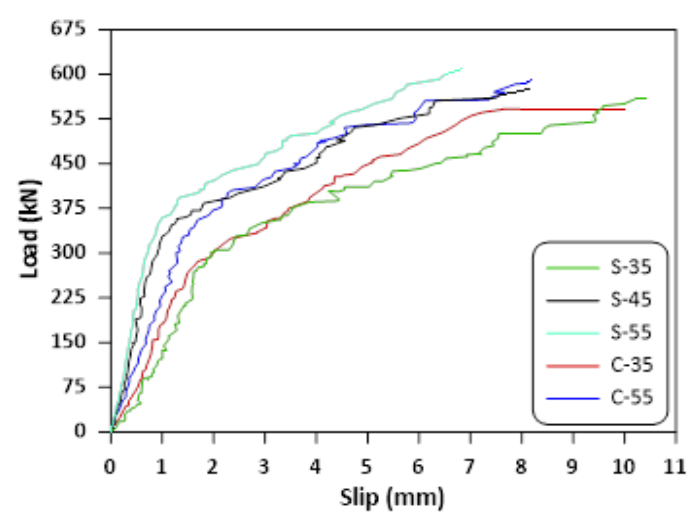

Figure 6 Load-slip relation for all specimens.

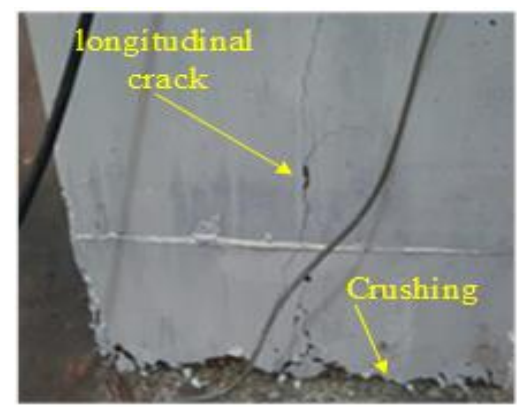

Figure 7 The failure mode of specimens.
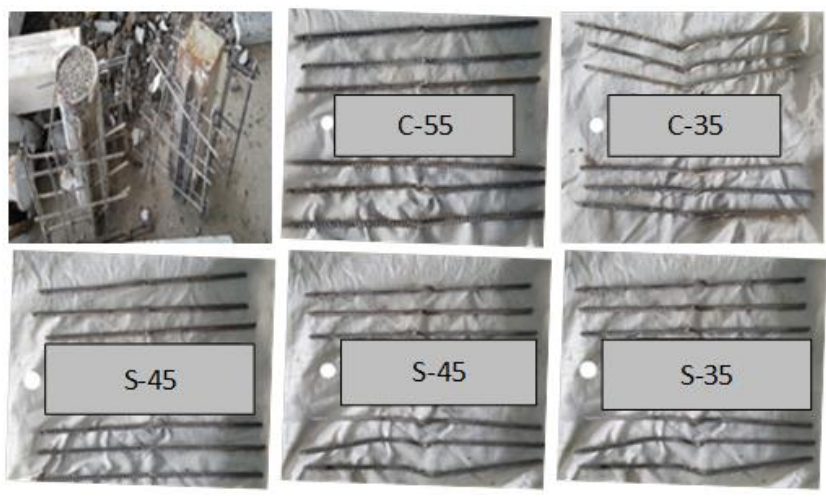

Figure 8 deformation of reinforcement bars.

One of the parameters of the study was observing the effect of concrete compressive strength. Fig. 9. shows the effect of compressive strength on load-deflection curves for samples of square CFST and circular CFST. From Table 4 and Fig. 9. the ultimate shear strength of specimens S-55, S-45, and S-35 were $608.34,575.2$, and $558.32 \mathrm{kN}$ respectively. From these results, it can conclude that the ultimate shear strength increases with an increase of concrete compressive strength. However, the maximum slip decreased with an increase in the compressive strength of concrete. The maximum slip of these specimens (S-55, S-45, and S-35) was $6.83,8.16$, and $10.43 \mathrm{~mm}$, respectively. The stiffness of the elastic stage (Ks) listed in Table 4. The stiffness of specimens S-55, S-45, and S35 were $379.79,328.28$, and $154.72 \mathrm{kN} / \mathrm{mm}$ respectively. The stiffness increased with the increase of the compressive strength of concrete. The same behavior is shown for specimens C-55, C-35, ultimate shear strength was 590.27 and $540.40 \mathrm{kN}$ for C-55, C-35, respectively. While the stiffness of these specimens were 234.01 and $175.92 \mathrm{kN} / \mathrm{mm}$, respectively. It can be concluded that by increasing the compressive strength of concrete, both of ultimate shear strength and stiffness of the samples are increased.

Section type CFST was the major parameter of the study. Fig. 10. shows the load-slip relation of perfobond connectors influenced by section type CFST. From Fig. 10. and Table 4 it can be noticed that the sample of circular section C-55 has ultimate shear strength less than that of the sample with square section S-35 at $590.27 \mathrm{kN}$ and $608.34 \mathrm{kN}$ respectively. The stiffness values of these samples were 379.79 and $234.01 \mathrm{kN} / \mathrm{mm}$, respectively. For other samples with $35 \mathrm{MPa}$ compressive strength it was also noted that the specimen of circular section C-35 has ultimate shear strength $540.40 \mathrm{kN}$, which was less than the specimen of square section S-35 that has $558.32 \mathrm{kN}$. Nevertheless, note the stiffness of these specimens showed a different behavior where the stiffness decreases despite increasing the ultimate shear strength. 


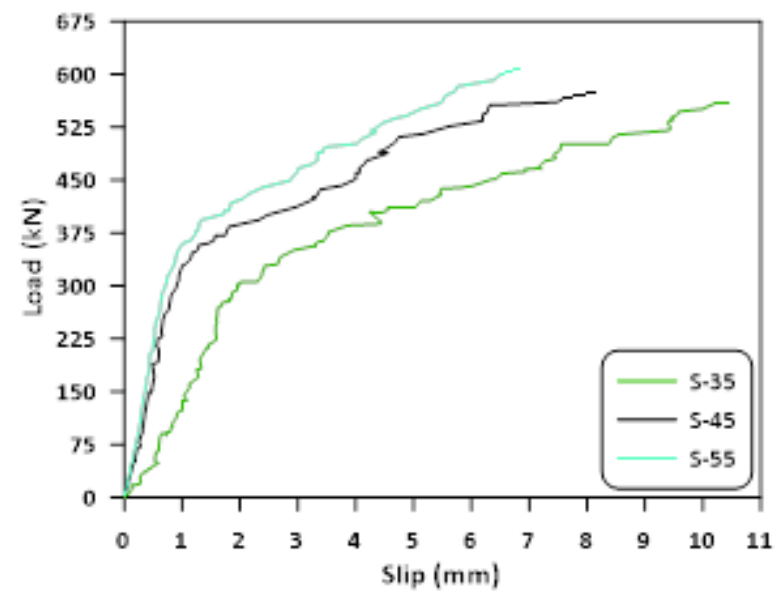

(a) Square CFST

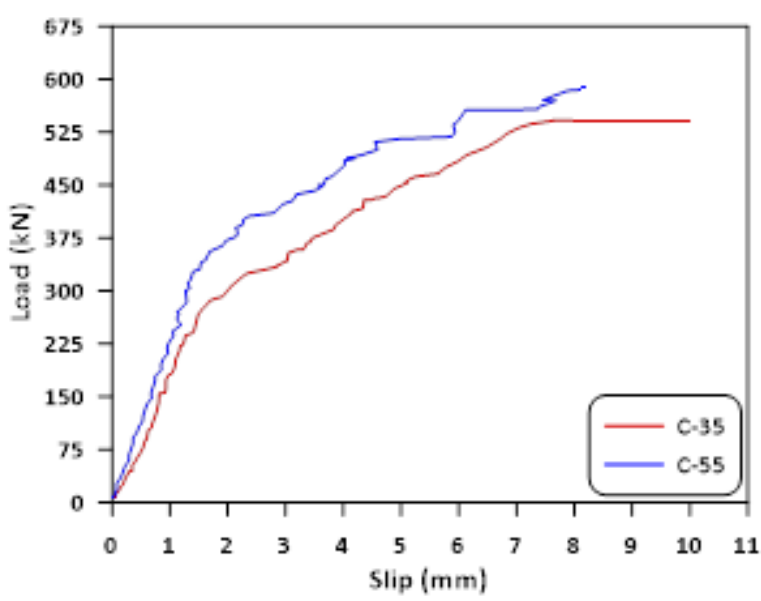

(b) Circular CFST

Figure 9 Effect of concrete compressive strength.

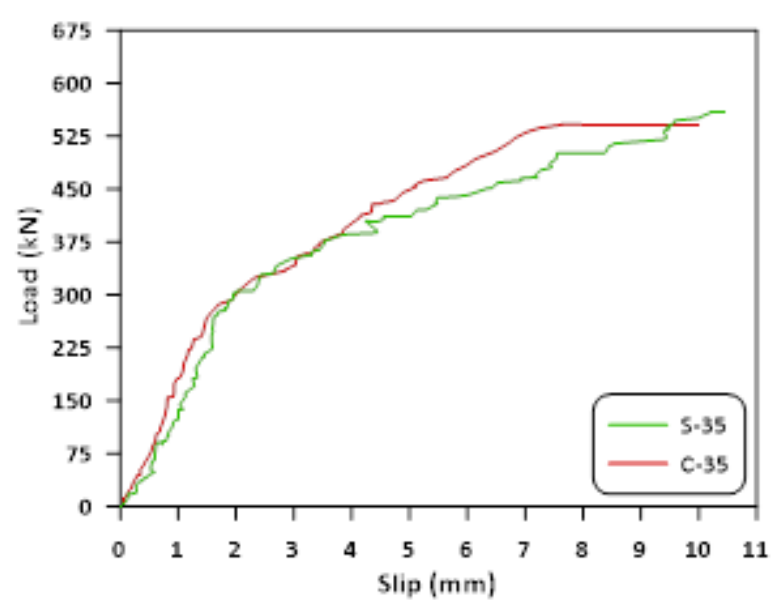

(a) Specimens of $35 \mathrm{MPa}$ compressive strength.

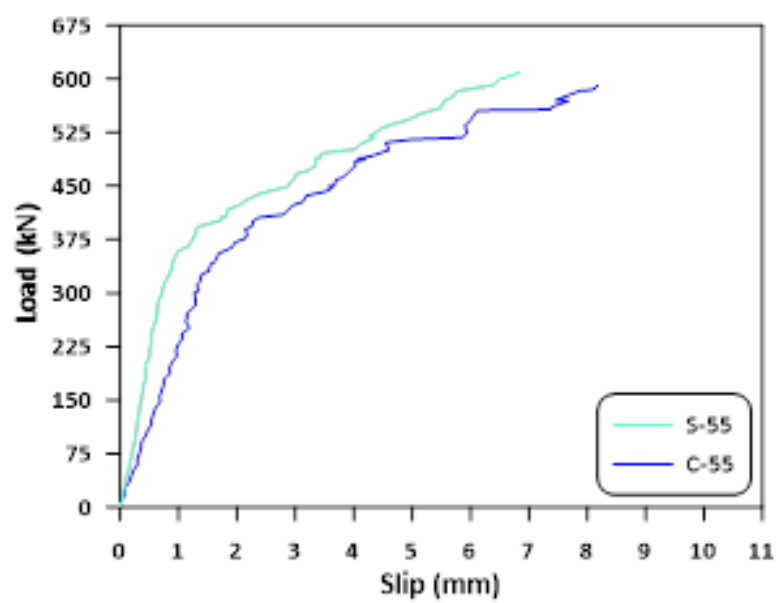

(b) Specimens of $55 \mathrm{MPa}$ compressive strength.

Figure 10 Effect of CFST section type.

\section{Conclusion}

The followings are the most important concluding remarks from the experimental work conducted in this study:

1. For the samples have a square CFST, the ultimate shear strength of the tested samples reduced by $5.44 \%$ when a concrete compressive strength of the blocks decreased from 55 to $45 \mathrm{MPa}$. While more decrease of $8.22 \%$ was recorded when the compressive strength was decreased further to $35 \mathrm{MPa}$.

2. For the samples have a circular CFST, the ultimate shear strength of the tested specimens reduced by $8.26 \%$ when a concrete compressive strength of the blocks decreased from 55 to $35 \mathrm{MPa}$
3. The sample with a square steel tube exhibited higher ultimate shear strength and stiffness than the sample with a circular steel tube.

4. The stiffness of the tested samples reduced by $13.56 \%$ when the concrete compressive strength of the blocks decreased from 55 to $45 \mathrm{MPa}$. While a more decrease of $59.26 \%$ recorded when the compressive strength decreased further to $35 \mathrm{MPa}$, for the samples have a square CFST.

5. The stiffness values of the tested samples reduced by $24.82 \%$ when the concrete compressive strength of the blocks decreased from 55 to $35 \mathrm{MPa}$, for the samples have a circular CFST.

6. In general, when the concrete compressive strength increased, the maximum slip is reduced. For the samples have a square 
CFST, the maximum slip was $6.83,8.66$, and $10.93 \mathrm{~mm}$ when the concrete compressive strength was 55,45 , and $35 \mathrm{MPa}$, respectively. While for the samples have a circular CFST, the maximum slip was 8.19 and $9.99 \mathrm{~mm}$ when the concrete compressive strength was 55 and $35 \mathrm{MPa}$, respectively.

\section{REFERENCES}

[1] W. Lorenc and E. Kubica, 'Behavior of composite beams prestressed with external tendons: Experimental study', Journal of Constructional Steel Research, vol. 62, no. 12, pp. 1353-1366, Dec. 2006.

[2] W. Xue, M. Ding, H. Wang, and Z. Luo, 'Static Behavior and Theoretical Model of Stud Shear Connectors', Journal of Bridge Engineering, vol. 13, no. 6, pp. 623-634, Nov. 2008.

[3] A. Prakash, N. Anandavalli, C. K. Madheswaran, and N. Lakshmanan, 'Modified Push-out Tests for Determining Shear Strength and Stiffness of HSS Stud Connector-Experimental Study', International Journal of Composite Materials, vol. 2, no. 3, pp. 22-31, Aug. 2012.

[4] 'Analytical Model for Load-Slip Relationship of Perfobond Shear Connector Based on Push-Out Test'. [Online]. Available: https://www.ncbi.nlm.nih.gov/pmc/articles/PMC6337733/. [Accessed: 11Mar-2019].

[5] Ali Shariati, 'Various types of shear connectors in composite structures: A review', International Journal of the Physical Sciences, vol. 7, no. 22, Jun. 2012.

[6] S. Zheng, C. Zhao, and Y. Liu, 'Analytical Model for Load-Slip Relationship of Perfobond Shear Connector Based on Push-Out Test', Materials, vol. 12, no. 1, p. 29, Dec. 2018.
[7] E. C. Oguejiofor and M. U. Hosain, 'Numerical analysis of push-out specimens with perfobond rib connectors', Computers \& Structures, vol. 62, no. 4, pp. 617-624, Feb. 1997.

[8] J.-H. Ahn, C.-G. Lee, J.-H. Won, and S.-H. Kim, 'Shear resistance of the perfobond-rib shear connector depending on concrete strength and rib arrangement', Journal of Constructional Steel Research, vol. 66, no. 10, pp. 1295-1307, Oct. 2010.

[9] S. Zheng, Y. Liu, T. Yoda, and W. Lin, 'Parametric study on shear capacity of circular-hole and long-hole perfobond shear connector', Journal of Constructional Steel Research, vol. 117, pp. 64-80, Feb. 2016.

[10] Q. T. Su and D. F. Wang, 'Strength and Stiffness of Corrugated Rib Connector', Advanced Materials Research, vol. 243-249, pp. 1497-1503, May 2011.

[11] S. Li, L. Su, and Z. Sun, 'Research on the Load-slip Properties of Corrugated Rib Connectors' Push-out Test', KSCE Journal of Civil Engineering, vol. 22, no. 4, pp. 1258-1264, Apr. 2018.

[12] S. Zheng, C. Zhao, and Y. Liu, 'Parametric Push-Out Analysis on Perfobond Rib with Headed Stud Mixed Shear Connector', Advances in Civil Engineering, vol. 2019, pp. 1-16, Mar. 2019.

[13] A. M. Ibrahim, H. M. Mubarak, and A. I. Said, 'Experimental study of push-out test of circular steel tube with various types of shear connectors', in 2018 1st International Scientific Conference of Engineering Sciences 3rd Scientific Conference of Engineering Science (ISCES), Diyala, 2018, pp. 265-270.

[14] S. Zheng, Y. Liu, Y. Liu, and C. Zhao, 'Experimental and Numerical Study on Shear Resistance of Notched Perfobond Shear Connector', Materials, vol. 12, p. 341, Jan. 2019.

[15] A. Modz, 'Eurocode 4: Design of composite steel and concrete structures -part 1-1: General rules and rules for buildings'. 